\title{
DISTRIBUCION Y DISPERSION DEL MIELERO (Coereba flaveola, AVES: COEREBIDAE) EN LA CIUDAD DE LIMA, PERU
}

Oscar González M. ${ }^{1}$

\section{Resumen}

El mielero (Coereba flaveola), es un ave introducida en la ciudad de Lima desde 1992, la cual tiene un patrón de dispersión selectivo. Hasta la fecha (Marzo 1999), no ha colonizado todos los distritos localizados en el Norte u Oeste de la ciudad. Esta selectividad podría deberse a que estos lugares no ofrecen un hábitat óptimo y/o a la falta de corredores naturales para su dispersión. En la actualidad, el mielero se ubica únicamente en parques y jardines de considerable cobertura arbórea.

Palabras clave: mielero, Coereba flaveola, aves, dispersión, distribución, Ecología Urbana, Lima.

\section{Abstract}

The bananaquit (Coereba flaveola), is a bird that has been introduced in the city of Lima since 1992. This species has a pattern of selective dispersion in the city. To date (March 1999) it has not colonized all the districts located to the North and West of the city. This selectivity suggest that these places do not offer an optimal habitat, and/or that the lack of natural corridors for dispersion is very important for this species. Up to now, the bananaquit is located only in parks and gardens with considerable arboreal coverage.

Keywords: bananaquit, Coereba flaveola, birds, dispersion, distribution, Urban Ecology, Lima.

\section{Introducción}

El estudio de invasiones de aves exóticas es importante para entender posibles cambios en procesos ecológicos los cuales pueden conducir al desequilibrio ecológico, y por ende a perdidas económicas de gran escala. Sin embargo, y a pesar de su importancia, la mayoría de estos estudios solo se limitan a reportar la presencia de aves exóticas, sin hacer un seguimiento de las especies (o poblaciones) para entender los patrones de dispersión y distribución, los cuales podrían proporcionar mayor información que nos permita contrarrestar sus efectos en otras especies (o poblaciones) de aves nativas (Temple ,1992).

El mielero (Coereba flaveola), es una especie de ave paseriforme introducida en la ciudad de Lima en 1992 por comerciantes de aves silvestres. La subespecie es C.f. pacifica, y es originaria de la costa norte del Perú. Esta especie se encuentra adaptada al ecosistema urbano (González, 1998). Hasta el mes de Junio de 1997, el mielero fue detectado en 21 distritos (aproximadamente 750 Has.) ubicados en el Centro, Sur y Este de la ciudad de Lima. Debido a que es una especie conspicua en estas localidades ha sido considerada en la categoría de “común” (González et al., 1998). El presente estudio tiene por objetivo actualizar la información sobre la distribución del mielero, e inferir cual es el patrón de dispersión en la actualidad.

\section{Lugar de estudio}

La ciudad de Lima se ubica en la costa central del Perú ( $\left.12^{\circ} 4^{\prime} \mathrm{S}, 77^{\circ} 2^{\prime} \mathrm{O}\right)$; en el valle del río Rímac y en las partes bajas de los valles del río Chillón y del río Lurín. El clima es árido y corresponde a la denominada ecorregión del Desierto del Pacífico (Brack, 1986).

\section{Métodos}

Se hicieron salidas de reconocimiento en parques y jardines de los distritos de Lima en los cuales aun no se habían registrado mieleros. Estas áreas verdes fueron seleccionados previamente con el uso de mapas del Servicio de Parques (SERPAR) de la ciudad de Lima, usando como criterios de selección: a) Areas de gran tamaño con abundante cobertura arbórea, los cuales corresponden a los denominados Parques Zonales, b) Parques de menor tamaño pero con abundante cobertura arbórea, y c) Cementerios, pues estos pueden ser refugios de aves (Lussenhop, 1977), y en especial de especies nectarívoras por la presencia de flores. Se efectuó una visita a cada área verde previamente escogida (Tabla 1) la cual duró 15 minutos aproximadamente. Los métodos de registro de mieleros fue a través de la observación directa con binoculares ( 7 x $35 \mathrm{~mm}$ ) y audición de vocalizaciones.

\section{Resultados y discusión}

En la actualidad, la distribución del mielero corresponde a la de 1997 (González, 1998) pues no se hallaron mieleros en las localidades visitadas. Esta información es muy importante porque nos indica que esta especie exótica no se esta dispersando rápidamente. Sin embargo, por registros no confirmados de esta especie realizados en Chaclacayo, indicarían una tendencia de expansión hacia el Este de la ciudad (Figura 1). Otro registro respecto a su dispersión fue la observación de dos individuos anillados en un árbol de "tipa" (Tipuana tipu) a $250 \mathrm{~m}$ del parque donde fueron 


\begin{tabular}{|c|c|c|c|}
\hline AREA & DISTRITO & LUGAR & FECHA \\
\hline CENTRO & Lima & Parque La Reserva & 28 Enero \\
\hline CENTRO & El Agustino & Parque Zonal Cahuide & 6 Febrero \\
\hline NORTE & Rímac & Av. Gamarra & 28 Enero \\
\hline NORTE & San Martín de Porras & Urb. Ingeniería & 28 Enero \\
\hline NORTE & Los Olivos & Parque Zonal Lloque Yupanqui & 28 Enero \\
\hline NORTE & Comas & Parque Zonal Sinchi Roca & 28 Enero \\
\hline NORTE & San Juan de Lurigancho & Parque Zonal Huiracocha & 6 Marzo \\
\hline OESTE & Bellavista & Parque vecinal & 6 Febrero \\
\hline OESTE & La Punta & Malecón & 6 Febrero \\
\hline OESTE & Callao & \multicolumn{2}{|c|}{ Cementerio Baquíjano y Británico 6 Febrero } \\
\hline ESTE & Huachipa & Refinería La Pampilla & 13 Marzo \\
\hline
\end{tabular}

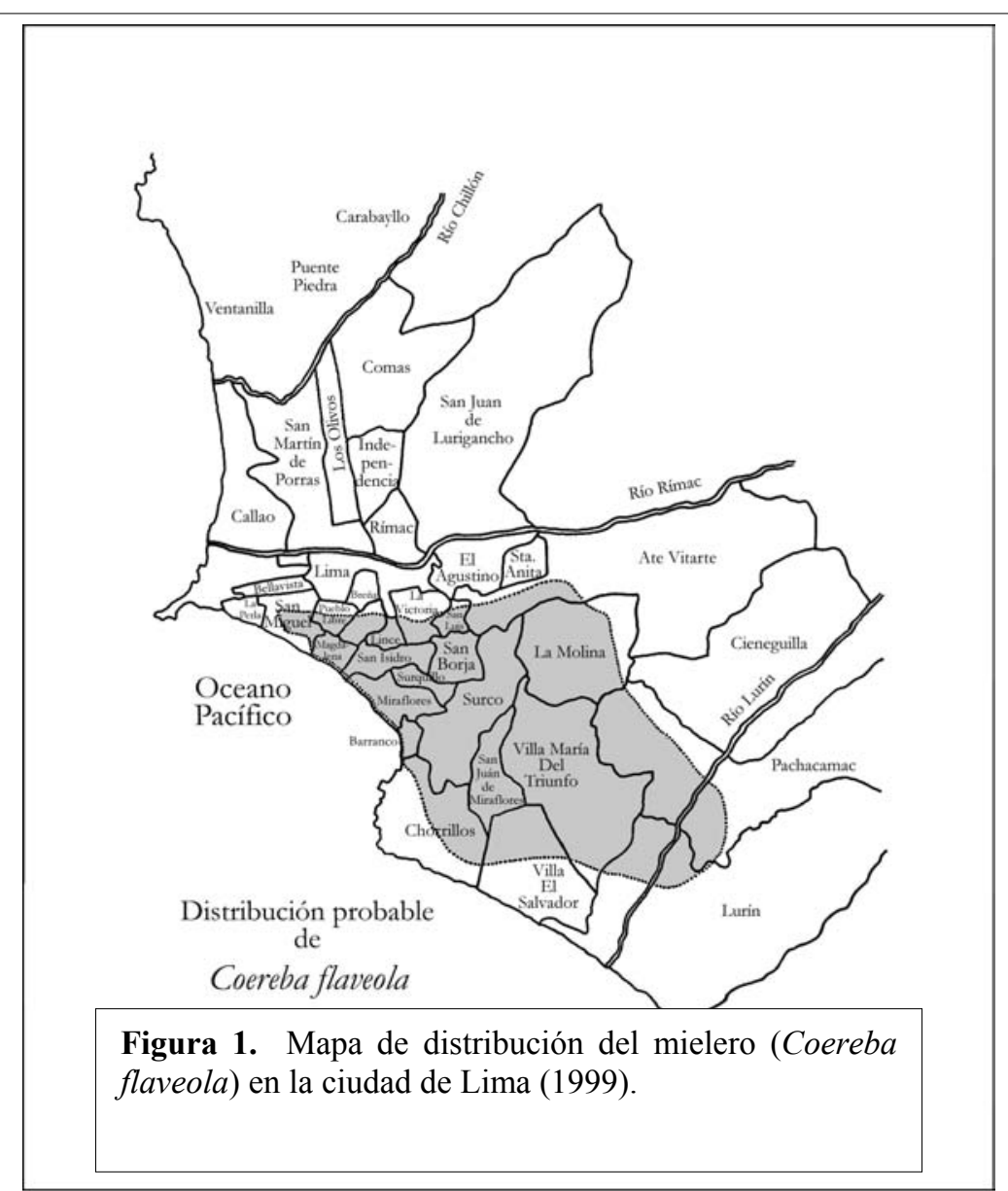

anillados (Surquillo) el día 25 de Abril de 1999. Ambos eran adultos y su comportamiento asemejaba al cortejo (emitían llamados y cantos y se desplazaban activamente entre el follaje del dosel). Por la disposición de los anillos, se sabe que uno de los individuos fue anillado el 23 de agosto de 1997, siendo juvenil; mientras que el otro podría ser anterior al 26 de Junio de 1997. La confirmación de estos registros sugeriría que la dispersión del mielero avanza lentamente en Lima.

Las áreas verdes del Norte y Oeste de la ciudad de Lima no tienen abundante cobertura arbórea, y no son lo suficientemente grandes como para atraer una buena diversidad de aves. Luego de un año y 3 meses, el mielero aun no se expande a los distritos del Norte de la ciudad (González, 1998). Debido al hábitat usado por el mielero (lugares con cobertura regular y flores), se sugiere que la dispersión es selectiva, y por lo tanto esta especie que no ha podido colonizar más áreas por no cumplir estas con sus necesidades de reproducción y alimentación, y/o a que estas áreas carecen de corredores los cuales son muy importantes para la dispersión y migración de las aves terrestres (Haas, 1995).

\section{Agradecimiento}

Agradezco a Daniel Huamán (ASIO S. R. L.) por el diseño del mapa.

\section{Referencisa bibliográficas}

Brack A. 1986. Gran Geografía del Perú. Vol II. Manfer-Juan Mejía Baca. España.

González O. 1998. Coereba flaveola, un ave nueva en el ecosistema de parques de la ciudad de Lima. Ecología. 1(1): 79-83.

González O., Pautrat L. \& González J. 1998. Las Aves más comunes de Lima y alrededores. Grupo Aves del Perú. Editorial Santillana. Lima.

Haas C. 1995. Dispersal and Use of Corridors by Birds in wooded patches on an agricultural landscape. Conservation Biology. 9(4): 845-854.

Lussenhop J. 1977. Urban cemeteries as bird refuges. Condor. 79: 456-461.

Temple S.A. 1992. Exotic birds: a growing problem with no easy solution. Auk. 109: 395-396. 